\title{
Uma sequência didática com experimentação no ensino do efeito fotoelétrico
}

Mikael Souto Maior de Sousa* Wladimir Ferreira Parente ${ }^{* *}$

\begin{abstract}
Resumo:
A Física Moderna e Contemporânea (FMC) está presente no cotidiano e graças aos seus avanços tecnológicos foram possíveis hoje temos aparelhos como smartphones, notebooks, GPS, etc. Devido à importância desse ramo da física estar presente no cotidiano dos educandos, faz-se necessário, como se prevê na Base Nacional Comum Curricular (BNCC), a inserção desse ramo no ensino básico. Entretanto, muitas vezes essa nova física é deixada de lado às vezes por despreparo por parte dos professores e às vezes por questões conteudistas no que tange os processos de vestibulares/ENEM. Sendo assim, este trabalho visou a implementação de uma sequência didática para o ensino de Física Moderna, em especial ao processo de quantização da energia e o efeito fotoelétrico, através de abordagens metodológicas ativas buscando dar significância aos conteúdos abordados para os discentes do Ensino Básico.
\end{abstract}

\section{Palavras-chave:}

Ensino de Física. Efeito fotoelétrico. Unidades de ensino potencialmente significativas.

\begin{abstract}
:
Modern physics is present in our lives and thanks to its technological advances, it was possible today to develop devices such as smartphones, notebooks, GPS etc. Due to the importance of this branch of physics being present in the daily life of students, it is necessary, as foreseen in the National Common Curricular Base (BNCC), the insertion of this branch in basic education. However, in many cases this new physics is sometimes neglected by teachers' insecurity and sometimes by contentious questions regarding the entrance exams/ENEM processes. Therefore, this research aims at implementation of Modern Physics teaching, in particular the energy quantization process and the photoelectric effect, through active methodological approaches seeking to give meaning to the contents addressed to the students of the basic education.
\end{abstract}

\section{Keywords:}

Physics teaching. Photoelectric effect. Potentially significant teaching units.

\footnotetext{
* Doutor em Física pela Universidade Federal da Paraíba. Professor colaborador no MNPEF - Polo 38/UFRR. E- mail: mikael. souto@ufrgs.br. ORCID iD: http://orcid.org/0000-0001-5605-2174.

** Licenciado em Física pela Universidade Estadual de Roraima. Mestrando em Física pelo Programa MNPEF - Polo 38/UFRR. E-mail: wladimirparente@gmail.com. ORCID iD: http://orcid.org/0000-0003-0970-1950.
} 


\section{Introdução}

A ciência e a tecnologia têm avançado em prol da melhoria na qualidade de vida da população principalmente em questões de saúde e de geração de energia elétrica. De acordo com a Base Nacional Comum Curricular, "a Ciência e a Tecnologia tendem a ser encaradas não somente como ferramentas capazes de solucionar problemas, tanto os dos indivíduos como os da sociedade, mas também como uma abertura para novas visões de mundo" (BRASIL, 2017, p. 547).

Aprender Física Moderna e Contemporânea (FMC) faz com que o estudante entenda o mundo em que vive, principalmente no que diz respeito às tecnologias. Valadares e Moreira (1998) falam da importância de se introduzir conceitos básicos de Física Moderna fazendo sempre uma ligação entre a física da sala de aula e a física do cotidiano do aluno.

É importante que a física seja reconhecida não como um produto que se encontra pronto, mas como um processo ocorrido ao longo da história da humanidade e que contribui no desenvolvimento de diferentes tecnologias, sendo ainda impulsionado por elas (BRASIL, 2002).

De acordo com Mozena (2014, p. 327), a BNCC é apresentada "como uma promessa de regular a educação básica no país e melhorar a qualidade do seu ensino reconhecido como falido". Porém, destaca que essa base pode servir para um retrocesso, pois formaliza o ensino focado em rankings, tendo a qualidade da educação a característica de algo mensurável (MOZENA, 2014).

Dentre as competências específicas de Ciências da Natureza e suas Tecnologias para o Ensino Médio presentes na BNCC, destaca-se "analisar situações-problema e avaliar aplicações do conhecimento científico e tecnológico e suas implicações no mundo" (BRASIL, 2017, p. 539). Sendo assim, as escolas podem adotar um currículo no qual a FMC se encaixe e os alunos tenham a oportunidade de entender que a física explica o mundo ao qual pertence.

Neste trabalho será tratado mais especificamente o efeito fotoelétrico através da realização de experimentações de baixo custo e simulação computacional como forma de buscarmos um conhecimento educacional de natureza própria, que em sala de aula extrapole a relação de conteúdos científicos matematizados, fazendo uma ligação direta das relações teoria-prática capaz de contribuir na formação dos estudantes. Tal motivação, para realização deste material surgiu devido a um levantamento do quadro de ensino de Física Moderna na cidade de Boa Vista - RR.

\section{A experimentação e o ensino de física}

A experimentação no ensino de física é forte aliada ao que os PCNs nos pedem quanto ao fato de desenvolvermos a capacidade interpretativa dos alunos acerca do tema estudado e dos problemas do seu dia a dia (BRASIL, 2000). Cremos que, para fortalecer os conceitos expostos em aulas teóricas, há necessidade da aula prática, momento no qual as teorias se exteriorizam e o aluno pode visualizar o que aprendeu teoricamente.

De acordo com Borges (2002), existe uma preocupação na exacerbada com a apresentação de conceitos e fórmulas tanto no ensino básico como nas universidades sem uma integralidade entre o ensino experimental e teórico para consolidar de maneira significativa o conhecimento do fenômeno em si, tornando-o mais motivador a aquisição do mesmo.

Seguindo as ideias de Gaspar e Monteiro (2005), ao levar a experimentação para a sala de aula, principalmente quando relacionada a conteúdos de física, pode-se promover uma ligação entre conteúdos formais e abstratos com conhecimentos prévios não formais trazidos pelo aluno, onde o mesmo pode fazer interpretações no espaço real e palpável.

Dessa forma, utilizamos a ideia de UEPS proposta por Moreira (2011), que são organizadas em oito etapas, para fazer uma sequência lógica que facilite a aprendizagem significativa dos educandos. É interessante observar também que para Vygotsky (1987), um conceito somente pode tornar-se consciente e submeter-se ao controle deliberado quando começa a fazer parte de um sistema. 
Seguindo as ideias de Ausubel et al. (1980), subsunçor é uma estrutura altamente organizada na estrutura cognitiva onde há uma hierarquia conceitual, capaz de armazenar experiências prévias do sujeito. Quando o aluno não dispõe de subsunçores ou os subsunçores existentes não são suficientes e nem satisfatórios para serem utilizados na aquisição de uma nova aprendizagem, deve-se utilizar de organizadores prévios.

\section{Aplicação da proposta de UEPS para o ensino de Física Moderna}

O produto educacional proposto segue, como é mostrado em Parente (2019), que trata da montagem dos experimentos e explicação detalhada da proposta. Foi aplicado no Colégio de Aplicação da Universidade Federal de Roraima em duas turmas de terceira série do Ensino Médio, cada turma continha 25 alunos, totalizando 50 indivíduos. Nessa instituição as aulas de física acontecem uma vez por semana e são dois tempos de aula seguidos por turma.

\section{Aplicação da sequência}

Seguindo as oito etapas da UEPS, como propõe Moran (2015). No primeiro encontro, que corresponde a duas aulas conjugadas, definimos o tópico a ser abordado, que seria a quantização da energia e o efeito fotoelétrico. Além disso, foi passado para os alunos um experimento, que consistia num dispositivo LED conectado a um sensor LDR, que controlava a luminosidade do LED. A partir daí, com os alunos observando e utilizando o aparato o segundo passo da UEPS foi abordado, onde o experimento serviu como um caminho para o levantamento de situações problemas para os alunos externalizarem seus conhecimentos prévios, ou subsunçores, segundo Ausubel et al. (1980).

Além disso, foi passado também um vídeo sobre o efeito fotoelétrico disponível no YouTube'1. Este vídeo serviu como âncora para trabalharmos o terceiro ponto da UEPS que trata da apresentação do conhecimento a ser ensinado/aprendido, partindo do aspecto mais geral para o mais específico.

Para finalizar a aula, os alunos responderam um questionário sobre os conceitos abordados em sala de aula. Um dos questionários está representado na Figura 1. Como tarefa para casa foi pedido que os alunos elaborassem um mapa conceitual acerca dos assuntos tratados em sala de aula. A fim de promover uma reconciliação integradora. 
Figura 3 - Questionário de verificação de aprendizagem aplicado ao final do primeiro encontro
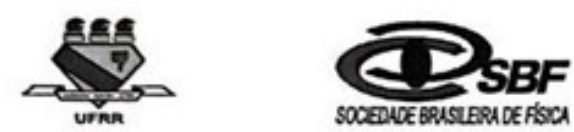

MNPEFE

QUESTIONÁRIO

a) O que você já leu, ouviu, ou viu sobre a quantizaçẫo da energia e o efeito fotoelétrico?

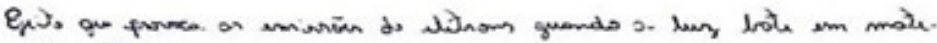
sid muitiea.

b) Onde o Efeito Fotoelétrico pode ser aplicado?

No enemes dor LOR" s mo Qulí

c) Em qual ramo da Fisica se estuda o Efeito Fotoelétrico?

No jake rodums tme fines griales

d) Como funciona a porta do shopping que abre sozinha quando voeê ehega perto?

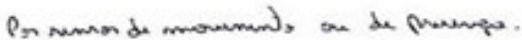

e) Por que as luzes dos postes acendem sozinhas em determinada hora do dia?

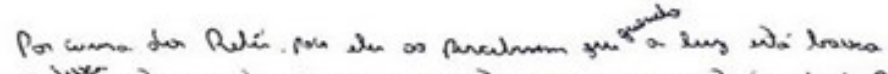

f) Como funcionam as placas de energia solar colocadas no telhado e em algumas caleuladoras?

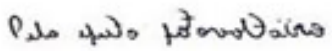

Fonte: Elaborado pelos autores.

\section{Segunda aplicação}

No segundo encontro, também com duas aulas conjugadas, as questões propostas na aula anterior foram discutidas em sala com o objetivo de fazê-los compreender o conteúdo tratado e sanar dúvidas e/ou conceitos inadequados que pudessem atrapalhar a construção do conhecimento. Notou-se que muitos alunos não participaram da discussão, talvez por insegurança ou falta de conhecimento dos assuntos tratados.

Em seguida, houve uma explanação sobre os mapas conceituais desenvolvidos. Alguns mapas foram escolhidos e mostrados para a turma a fim de promover uma discussão sobre os conceitos. Na Figura 2 estão representados alguns dos mapas elaborados. 
Figura 2 - Mapa conceitual elaborado por um aluno

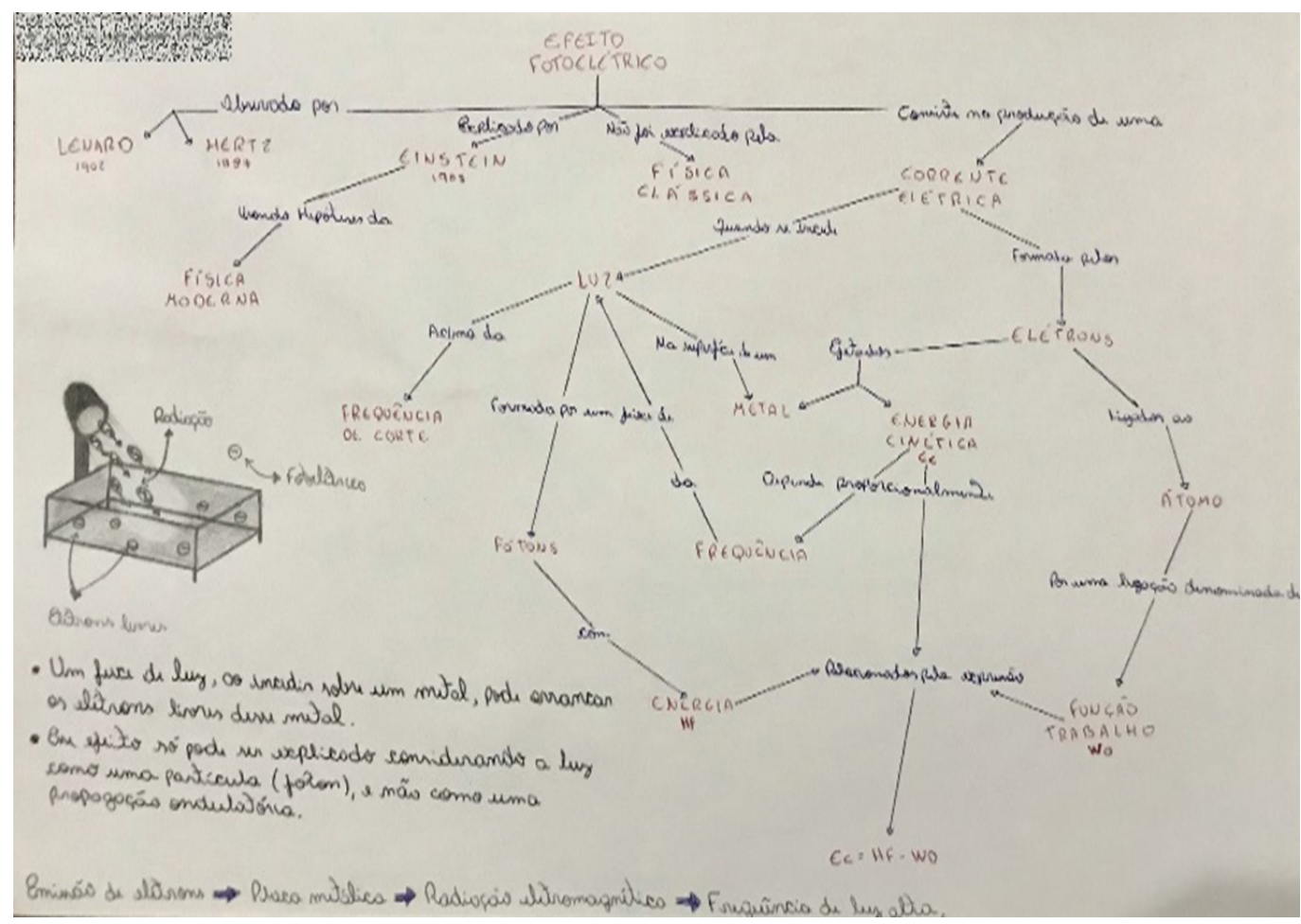

Fonte: Elaborado pelos autores.

Após a explanação, os alunos realizaram individualmente a leitura do texto "Dualidade Onda Partícula da Luz"2 , e destacaram no texto os tópicos que consideraram mais importantes. Após a leitura, se formaram grupos de três a quatro alunos e houve uma discussão sobre o texto.

\section{Terceira aplicação}

Foi apresentada uma aula expositiva, com slides e vídeos que tratam do contexto histórico e do desenvolvimento científico que explicam a quantização da energia. Após cada slide, foi pedido aos alunos que compartilhassem com a turma o que sabiam do conteúdo proposto, e a maioria dos alunos teve uma participação bastante proveitosa.

Com a finalidade de aprofundamento do conhecimento, os alunos foram levados para o laboratório de ciências e montaram um experimento voltado para a quantização da energia para se calcular a constante de Planck.

Tal experimento consiste em medir a tensão elétrica entre os terminais de um LED e calcular a constante de Planck. Os passos adotados foram: com a ajuda de um voltímetro, os alunos mediram a tensão elétrica entre os terminais de um LED; calcularam a energia, para em seguida calcularem a constante de Planck. Os detalhes da montagem e execução do experimento podem ser vistos em Parente (2019). 


\section{Quarta aplicação}

A aula foi iniciada com uma discussão sobre o experimento da aula anterior. Alguns alunos questionaram o porquê de o cálculo experimental não estar totalmente de acordo com o valor da constante de Planck contido no livro. Ressaltou-se que todo experimento é passível de erros e que o experimento, quanto mais fosse realizado corretamente, maior seria a aproximação do resultado numérico. Explicou-se que os erros sistemáticos, causados por fontes identificáveis, podem ter sido cometidos, como por exemplo o aluno acendeu muito o LED quando na verdade ele deveria estar muito fracamente aceso. Neste ponto, demos continuidade aos passos da nossa UEPS com a diferenciação progressiva dos conhecimentos.

Dando sequência à aula, exibiu-se um vídeo de um experimento sobre efeito fotoelétrico, sendo a primeira exibição desse vídeo feita sem o áudio, para que a turma tentasse explicar o que estava acontecendo durante a realização do experimento exibido, conforme a Figura 3.

Figura 3 - Vídeo de um experimento sobre o efeito fotoelétrico

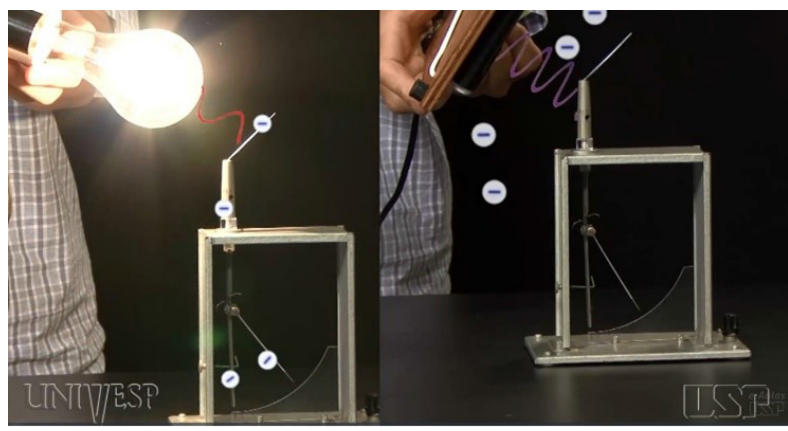

Fonte: Captura de tela do vídeo Tema 01 - Luz / Experimentos - Efeito fotoelétrico3.

Após esta etapa, iniciou-se uma aula expositiva para sistematização e aprofundamento do tema efeito fotoelétrico. Ao final da aula foi realizada uma atividade no modelo de questionário com perguntas e respostas no estilo de verdadeiro (V) ou falso (F) que serviu como avaliação qualitativa.

\section{Quinta aplicação}

Nessa aula realizou-se um experimento no qual se utilizou a simulação PhET para explicar o efeito fotoelétrico. Foi pedido aos alunos que calculassem a função trabalho de determinados materiais ao realizarem a simulação. O procedimento ocorreu conforme as seguintes etapas. Primeiro, na sala de informática solicitamos que os alunos acessassem um link $\mathrm{k}^{4}$ que contém a simulação computacional para executar a simulação. Em seguida, na segunda etapa, com a simulação aberta, solicitamos que os alunos selecionassem o material da placa fotoelétrica. Na terceira etapa solicitamos que os alunos controlassem o comprimento de onda da luz incidente até que os elétrons da placa parassem de ser emitidos (para determinar a frequência de corte).

Em todos as etapas é pedido aos alunos que anotem suas informações numa tabela. Na quarta etapa, com a tabela devidamente preenchida, pede-se para os alunos calcularem a função trabalho dos diferentes materiais. Por fim, na quinta etapa é solicitado que os alunos respondam o questionário com base em algumas informações sobre o comportamento da simulação quando variamos algum parâmetro físico, como a intensidade da luz ou a frequência da luz incidente sobre a placa por exemplo.

3. Link de acesso ao vídeo: https://www.youtube.com/watch?v=VVka6Mp5vyA.

4. Disponível em: https://phet.colorado.edu/en/simulation/legacy/photoelectric. 


\section{Resultados}

Como o trabalho foi baseado nas metodologias ativas, durante as aulas buscou-se a colaboração e a participação dos alunos. Segundo Moran (2015), através de metodologias ativas pode-se alcançar, no aluno, processos mais avançados de reflexão, de integração cognitiva e de generalização dos conteúdos.

Alguns questionários foram elaborados e as discussões acerca deles tiveram caráter qualitativo. A participação dos alunos durante o processo teve caráter qualitativo a fim de se notar a presença de aprendizagem significativa. As aulas seguiram as propostas das "Unidades de Ensino Potencialmente Significativas" de Moreira (2011), segundo as quais, nas primeiras fases das UEPS houve a organização do conhecimento a ser estudado, identificando-se os subsunçores - elementos disponíveis na estrutura cognitiva dos alunos —, elaborando-se organizadores prévios.

Partimos do pressuposto que muito dos alunos, ao serem abordados sobre a quantização de energia e efeito fotoelétrico, não teriam conhecimento desse fenômeno e nem conseguissem relacionar palavras-chave correlacionadas. Entretanto, muitos dos alunos já mostravam algum domínio sobre o conteúdo mesmo que intuitivamente.

Os resultados obtidos foram analisados através dos dados obtidos durante toda aplicação do produto educacional, sendo analisados, mapas conceituais, depoimentos de alunos, observação da postura dos alunos durante as atividades experimentais e participação dos mesmos durante toda aplicação da sequência didática. Como forma de controle também foi elaborado e aplicado dois questionários. O primeiro aplicado logo após a primeira aula. E o segundo aplicado ao fim do último encontro.

Alguns pontos interessantes nas aulas se deram com a participação ativa dos alunos. Podemos citar, por exemplo, a fala de três alunos que serão reproduzidas ipsis verbis a seguir. No primeiro encontro, ocorreu o seguinte diálogo:

"Professor, esse tal de LDR é o mesmo que aqueles que é usado naqueles sensor de abrir portão de casa com o carro né?"

"Sim, à medida que você incide luz sobre ele, a resistência varia com essa luminosidade".

"Então, eu tentei colocar no portão lá de casa, só que aí até com relâmpago tava abrindo sabe?! Aí eu fiz uma gambiarra pra ele receber só a luz do farol do carro de mãe, aí deu certo".

Aqui, percebemos para a promoção de um conhecimento significativo é necessário a busca pelos conhecimentos prévios dos alunos e, neste caso, a proposta desta UEPS foi bem sucedida.

No segundo encontro podemos destacar a seguinte fala da aluna: "Professor essa coisa de um elétron saltar de uma camada para outra no átomo tem a ver com as cores que os fogos de artifício soltam né?". Neste caso, percebe-se que a UEPS também foi bem sucedida pois nota-se claramente uma conexão do conhecimento tratado com uma situação real. Neste caso, os alunos conseguiram, após a explicação do professor sobre a pergunta da aluna, fazer uma ligação interdisciplinar entre a física do efeito fotoelétrico e quantização da energia, com os conhecimentos vistos sobre a história do átomo nas aulas de química do ano anterior.

Outro ponto interessante a se destacar foi a promoção do aluno como agente ativo da construção do conhecimento, onde propomos com essa UEPS que os alunos fossem capazes de despertar o companheirismo e ajudar uns aos outros nessa construção tomando o papel de protagonismo no decorrer das aulas.

Com a utilização do experimento como instrumento avaliativo, abriu-se espaço para que os alunos interagissem entre si. Assim, aqueles com mais familiaridade com a parte experimental puderam ajudar aqueles com mais dificuldades, trocando a todo momento experiências sobre o tema proposto pela UEPS, que tratava da quantização da energia e do efeito fotoelétrico. 


\section{Conclusões}

Criou-se como produto educacional uma sequência didática apoiada na proposta das Unidades de Ensino Potencialmente Significativas (UEPS) de Moreira (2011) em conjunto com as Metodologias Ativas de Moran (2015), no intuito de promover a aprendizagem significativa e não mecânica nos alunos. Tal sequência didática tem por objetivo introduzir o conteúdo da Quantização de Energia e o Efeito Fotoelétrico nas escolas públicas e particulares de Boa Vista - RR.

A utilização de tal metodologia mostra-se eficaz, onde o professor pode fazer avaliações qualitativas durante cada encontro, propondo um aprofundamento nos conteúdos de maneira progressiva e integradora. Pôde-se ainda atender, de maneira individual e durante a aula, aqueles estudantes que demonstraram maior dificuldade na compreensão dos temas propostos.

Para que este trabalho obtivesse êxito, faz-se necessário que o professor tome a postura de mediador, instigando os alunos durante o tempo de aula a participarem do processo. Explicou-se aos alunos que, para haver aprendizagem significativa, o material utilizado na aula seria potencialmente significativo, ou seja, teria lógica e seria atrativo, mas que eles deveriam participar das aulas, estar dispostos a aprender e, nos seus momentos fora da sala de aula, precisariam buscar mais sobre os conteúdos tratados.

O modelo de aula tradicional já não consegue suprir as necessidades dos alunos que, com a ajuda da tecnologia, têm acesso a muita informação numa velocidade enorme. Cabe ao professor mediar o uso dessas tecnologias e utilizá-las a favor da educação. Nas escolas que possuem laboratório de informática, a realização de atividades práticas de simulação pode contribuir com o professor na evolução intelectual dos estudantes.

\section{Referências}

AUSUBEL, David; NOVAK, Joseph; HANESIAN, Helen. Psicologia Educacional. 2. ed. Rio de Janeiro: Editora Interamericana, 1980.

BORGES, Antônio Tarciso. Novos rumos para o laboratório escolar de ciências. Caderno Brasileiro de Ensino de Física, Florianópolis, v. 19, n. 3, p. 291-313, 2002. Disponível em: https://periodicos.ufsc.br/index.php/fisica/article/ view/6607/6099. Acesso em: 28 abr. 2020.

BRASIL. Base Nacional Comum Curricular: educação é a base. Brasília, DF: MEC/Secretaria de Educação Média e Tecnológica, 2017.

BRASIL. Parâmetros Curriculares Nacionais: ensino médio. Brasília, DF: MEC/Secretaria de Educação Média e Tecnológica, 2002.

BRASIL. Orientações Educacionais Complementares aos Parâmetros Curriculares Nacionais: ensino médio. Brasília, DF: MEC/Secretaria de Educação Média e Tecnológica, 2000.

GASPAR, Alberto; MONTEIRO, Isabel. Atividades experimentais de demonstrações em sala de aula: uma análise segundo o referencial da teoria de Vygotsky. Investigações em Ensino de Ciências, Porto Alegre, v. 10, n. 2, p. 227-254, 2005. Disponível em: https://www.if.ufrgs.br/cref/ojs/index.php/ienci/article/view/518/315. Acesso em: 26 dez. 2019.

MORAN, José. Mudando a educação com metodologias ativas. In: SOUZA, Carlos Alberto de; MORALES, Ofelia Elisa Torres (org.). Coleção Mídias Contemporâneas. Convergências midiáticas, educação e cidadania: aproximações jovens. Ponta Grossa: Foca Foto-PROEX/UEPG, 2015. v. II, p. 15-33. Disponível em: http://www2.eca.usp.br/moran/ wp-content/uploads/2013/12/mudando_moran.pdf. Acesso em: 19 set. 2019.

MOREIRA, Marco. Unidades de ensino potencialmente significativas - UEPS. Aprendizagem Significativa em Revista, Porto Alegre, v. 1, n. 2, p. 43-63, 2011. Disponível em: https://www.if.ufrgs.br/ moreira/UEPSport.pdf. Acesso em: 13 ago. 2019.

MOZENA, Erika. Investigando enunciados sobre a interdisciplinaridade no contexto das mudanças curriculares para o ensino médio no Brasil e no Rio Grande do Sul. 2014. Tese (Doutorado em Ensino de Física) - Instituto de Física, Universidade Federal do Rio Grande do Sul, Porto Alegre, 2014. 
PARENTE, Wladimir. Uma sequência didática para a Física Quântica: a experimentação no ensino do efeito fotoelétrico. 2019. Dissertação (Mestrado profissional em Física) - Centro de Ciências Tecnológicas, Universidade Federal de Roraima, Boa Vista, 2019.

VALADARES, Eduardo; MOREIRA, Alysson. Ensinando física moderna no segundo grau: efeito fotoelétrico, laser e emissão de corpo negro. Caderno Brasileiro de Ensino de Física, Florianópolis, v. 15, n. 2, p. 121-135, 1998. Disponível em: https://periodicos.ufsc.br/index.php/fisica/article/view/6896/7584. Acesso em: 11 jul. 2019.

VYGOTSKY, Lev. Pensamento e linguagem. 1. ed. São Paulo: Martins Fontes, 1987.

Data de submissão: 29/04/2020

Data de aceite: 16/07/2020 